\title{
The Effects of Temperature on the Foraging Activity of Red Imported Fire Ant Workers (Hymenoptera: Formicidae) in South China
}

\author{
by \\ Yong-yue Lu*, Lei Wang, Ling Zeng \& Yi-juan Xu
}

ABSTRACT

In this study, we investigated the effects of temperature of the ambient air, ground surface, and the soil at 5 -cm deep on the foraging activity of the workers of red imported fire ant, Solenopsis invicta Buren, in South China with the method ofbait traps. Significant correlations were observed between the temperature and the foraging activity of fire ants. Specifically, when the ambient temperature was above $20^{\circ} \mathrm{C}$, the fire ants foraged actively, and the activity reached a maximum when the ambient temperature was between 25 to $33^{\circ} \mathrm{C}$. But the foraging activity decreased as the ambient temperature rose higher than $34^{\circ} \mathrm{C}$. Moreover, fire ants were found to forage at maximal rates with the soil surface temperature between 27 to $40^{\circ} \mathrm{C}$. The ants started foraging when the soil temperature at 5 -cm deep was between 16 to $48^{\circ} \mathrm{C}$, while $28 \sim 37^{\circ} \mathrm{C}$ was the optimal temperature for the foraging activity. The extreme temperature thresholds for foraging of the ambient air, soil-surface, and soil at 5 -cm deep were $11^{\circ} \mathrm{C} / 44^{\circ} \mathrm{C}, 10^{\circ} \mathrm{C} / 57^{\circ} \mathrm{C}$, and $12^{\circ} \mathrm{C} / 48^{\circ} \mathrm{C}$ respectively.

\section{INTRODUCTION}

The red imported fire ant, Solenopsis invicta, is an important invasive species. It originated from South America and was introduced into the United Sates of America (USA) in 1930s (Vazquez et al. 2003). Currently, fire ants inhabit about 129.5 million ha. in South USA and Puerto Rico (Williams et al. 2003). It was estimated that fire ants caused more than $\$ 1$-billion of economic loss each year in the southern states of USA (Wojcik et al. 2001). In China, this pest was first detected on September 28, 2004 (Zeng et al.

Red Imported Fire Ant Research Center, South China Agricultural University, Guangzhou 510640, China

*Correspondence address:luyongyue@scau.edu.cn 
2005), although Lu et al. (2008) inferred that the first fire ant infestation probably occurred as early as in the 1990s.

The amount of food collected by workers is critical for the colony's maintenance and reproduction (Bernstein 1979). Their forging activity is affected by many environmental factors, such as humidity, soil moisture, daylight, and temperature, among which temperature serving as a primary factor (Porter $\&$ Tschinkel 1987). More specifically, fire ants foraged when the temperature of the soil 2-cm deep was from 15 to $43{ }^{\circ} \mathrm{C}$ in Florida (Porter \& Tschinkel 1987), while low temperature counteracted the ants' forging (Lofgren et al. 1964). In addition, the time of the year when the fire ants reach their maximal forging activity varied from region to region (Vogt et al. 2003).

Quick adaptation to a new environment is an important characteristic of invasive species. Fire ants have shown rapid acclimatization when they were exposed to low temperatures (Xu et al. 2009). They can also develop quick adaptation and resistance to desiccation (Phillips et al. 1996; Xu et al. 2009). Furthermore, the climate and environment of China are greatly different from that of South America and the USA. Therefore, we hypothesized that the fire ants would show significant differences in foraging activity in China. To test this hypothesis, we first investigated the temperature thresholds for the foraging activity of $S$. invicta in South China in this study.

\section{MATERIALS AND METHODS}

\section{Study site}

This study was conducted from January to July of 2006 in Wuchuan, Guangdong, China. The size of study site was $4800 \mathrm{~m}^{2}(60 \mathrm{~m} \times 80 \mathrm{~m})$. More than $95 \%$ of the area was covered with grassy weeds.

\section{Mound density}

The social type of red imported fire ants at the study site was determined as polygyne. The active mounds were video-recorded every time before bait traps were set.

\section{Ant Worker sampling}

Worker ants were sampled at bait traps. A total of 12 bait traps were set, with the distance of $6 \mathrm{~m}$ between every two traps. Early morning (6am), afternoon $(2 \mathrm{pm})$, and dusk $(6 \mathrm{pm})$ were chosen for ant collection. The sampling 
method was based on the previously reported one by Briano et al. (2002) with modifications. The bait trap contained a $30 \mathrm{~mL}$ plastic vial with a $5-\mathrm{mm}$ thick sausage inside. The traps were retrieved $30 \mathrm{~min}$ after they were set on the ground surface. All bait traps were shaded with white plates to keep cool and protect the fire ants from disturbance. Trapped ants were dipped into soapy water and counted. The numbers of captured ants were counted for further analysis.

Ant samples were collected four times in each month. In order to keep the traps at the same position every time, colorful flags were used to mark their positions. Ambient air temperature in shade $(\approx 1 \mathrm{~m}$ above ground level), unshaded soil-surface temperature, and soil temperature at 5-cm deep were measured at the same time when the traps were set. The temperature taken into further analysis was the mean of those at $6 \mathrm{am}, 2 \mathrm{pm}$, and $6 \mathrm{pm}$. The number of ant workers per trap was the mean of those captured by the 36 trap vials collected each day. The foraging was considered as active when the per-trap number of worker ants was over 30 individuals.

\section{Statistical analysis}

The correlations and models between the number of worker ants and the temperatures were analyzed by using Statistical Analysis System (SAS) (SAS Institute, 1985).

\section{RESULTS}

\section{Dynamics of active mound density}

The active mound densities varied slightly from January to July of 2011 (Fig.1). The minimum density was observed in February with 77.1 ants per ha, while the maximum was observed in June with 102.1 ants per ha.

\section{Effects of temperature on the foraging of worker ants}

The numbers of red imported fire ant workers captured in baited vials at different temperatures are listed in Table 1. From January to July in 2006, the ambient temperature ranged from 11.0 to $35.0^{\circ} \mathrm{C}$; the soil surface temperature ranged from 13.0 to $44.0^{\circ} \mathrm{C}$; and the soil temperature at $5-\mathrm{cm}$ deep ranged from 17.0 to $39.0^{\circ} \mathrm{C}$. The number of workers captured indicated that the foraging was active when the ambient temperature, the soil surface temperature, and the soil temperature at 5 -cm deep were above $20{ }^{\circ} \mathrm{C}, 22$ 


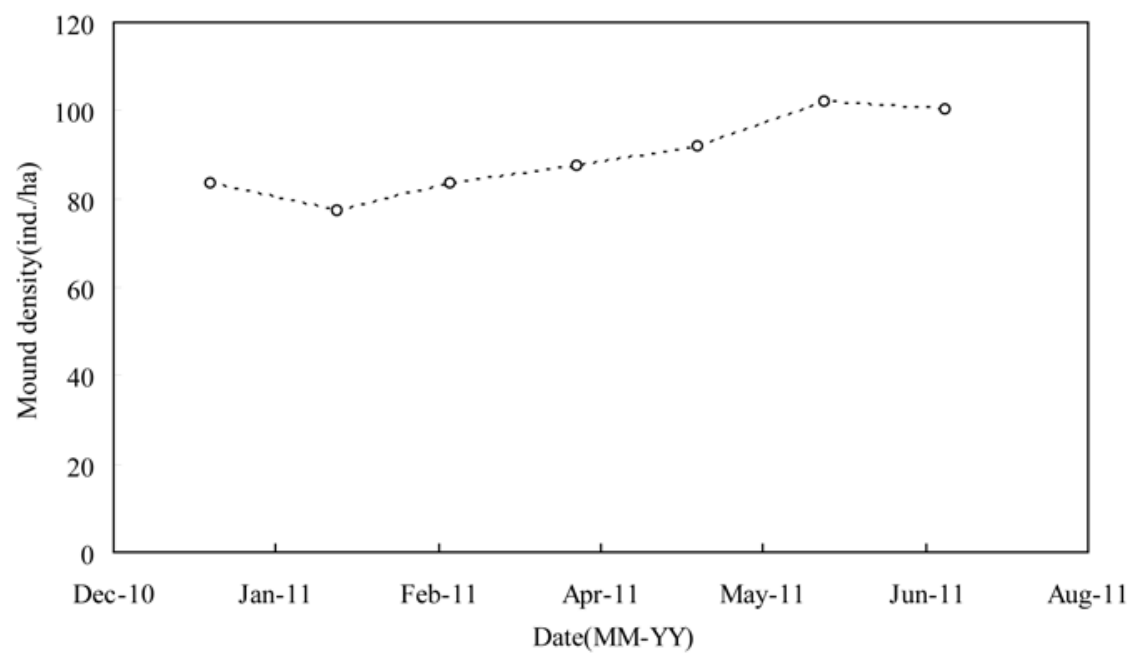

Fig. 1 Dynamics of the active mound density from June to July of 2011.

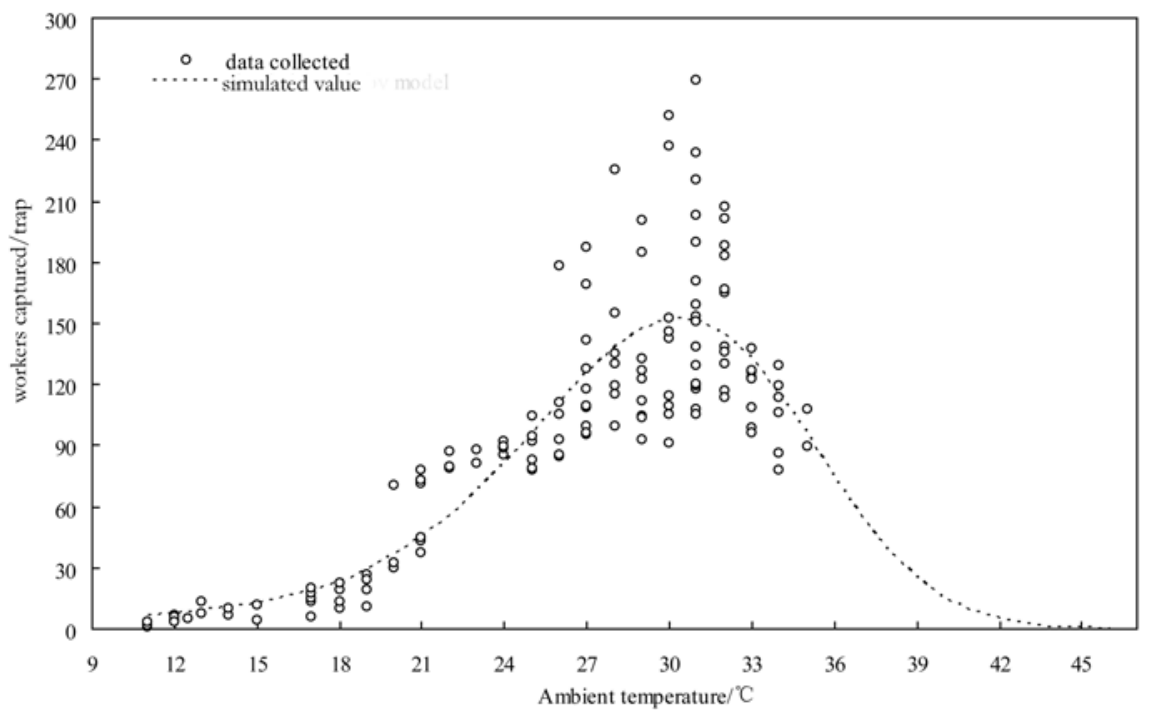

Fig. 2 Dynamics of red imported fire ant workers captured in baited vials at different ambient temperatures. Each point represents the average number of ants captured per bait trap $(\mathrm{N}=12)$. 


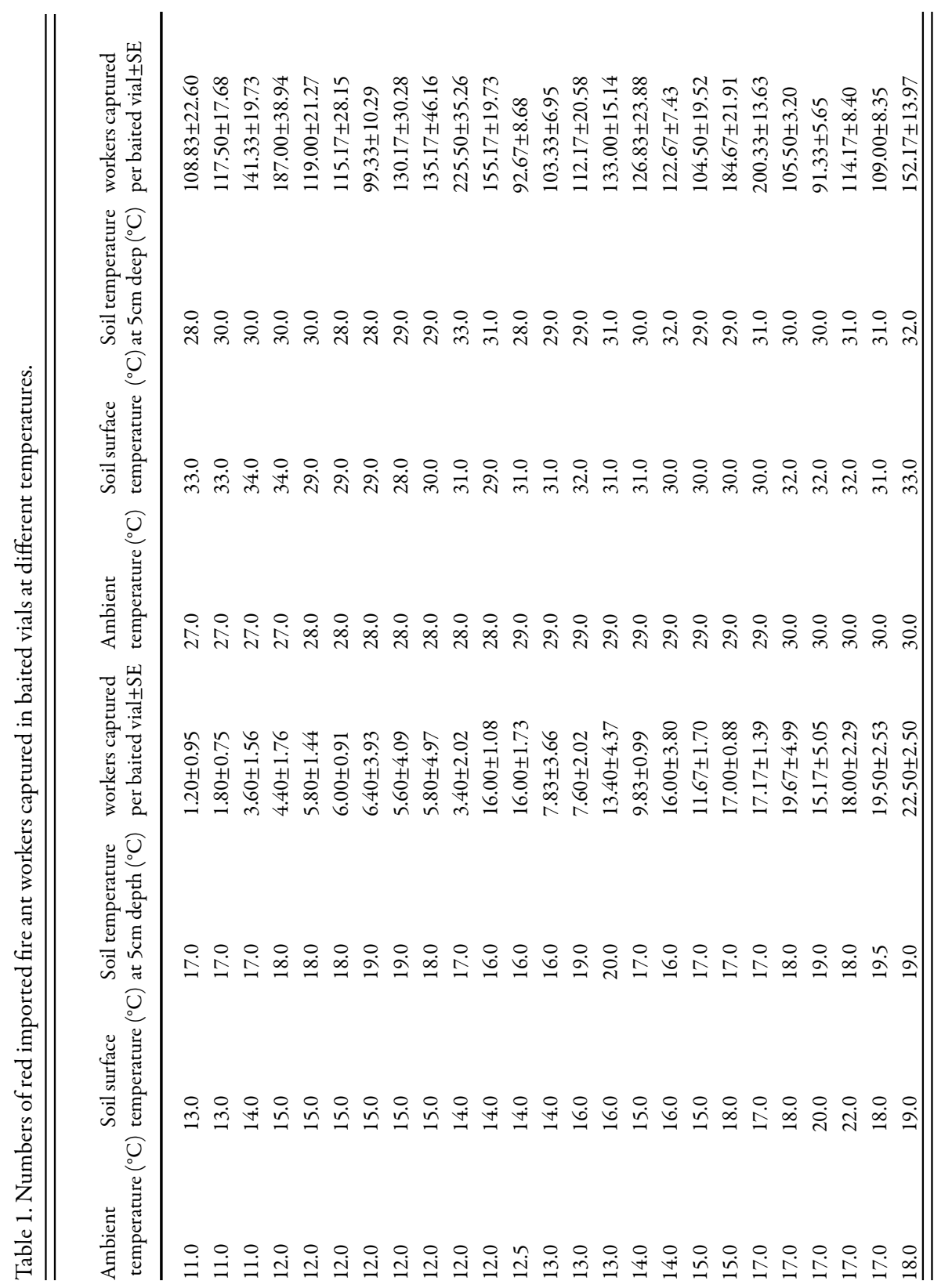




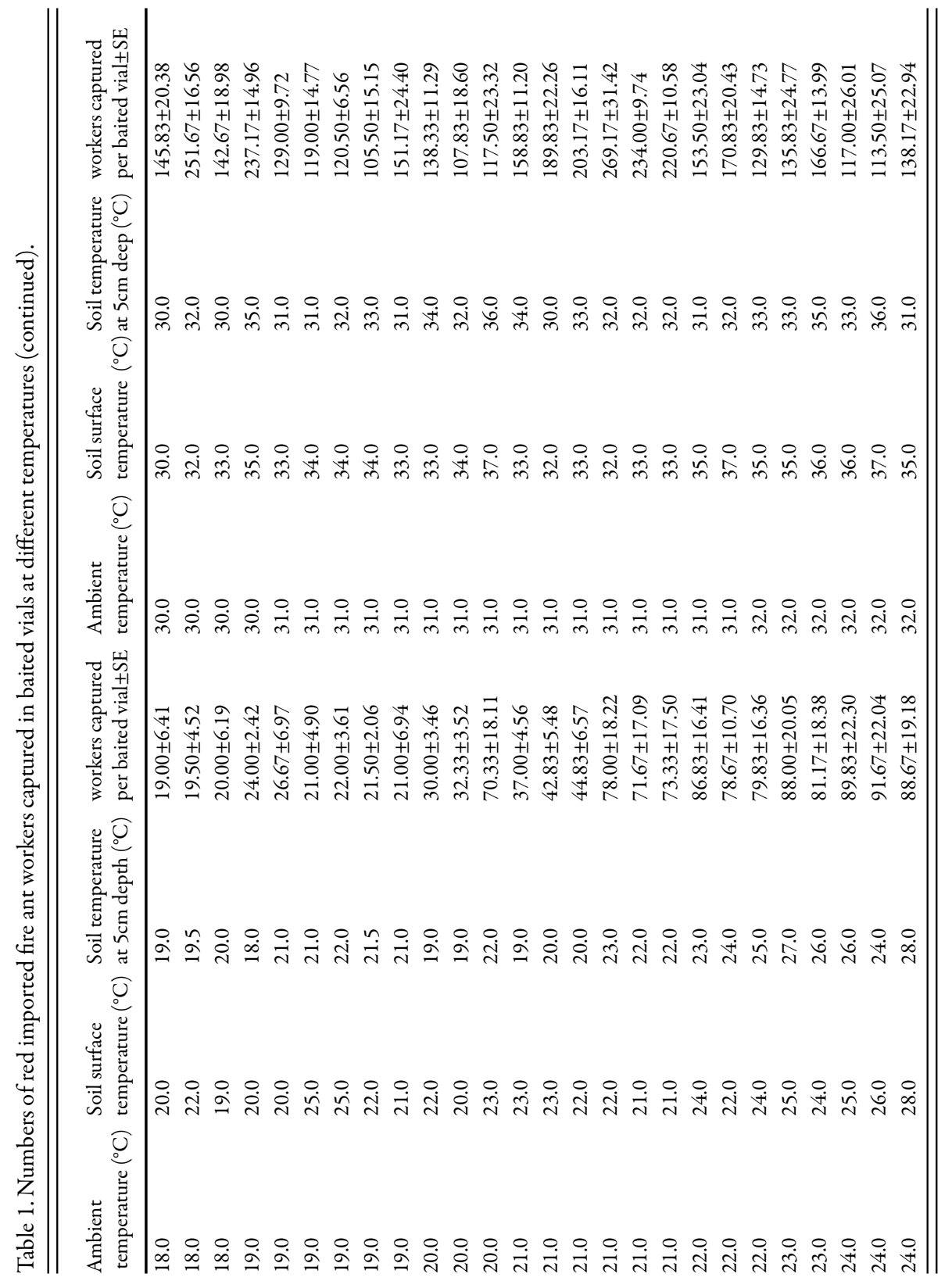


Lu, Y.-Y. et al. - Effects of Temperature on Fire Ant Foraging Activity

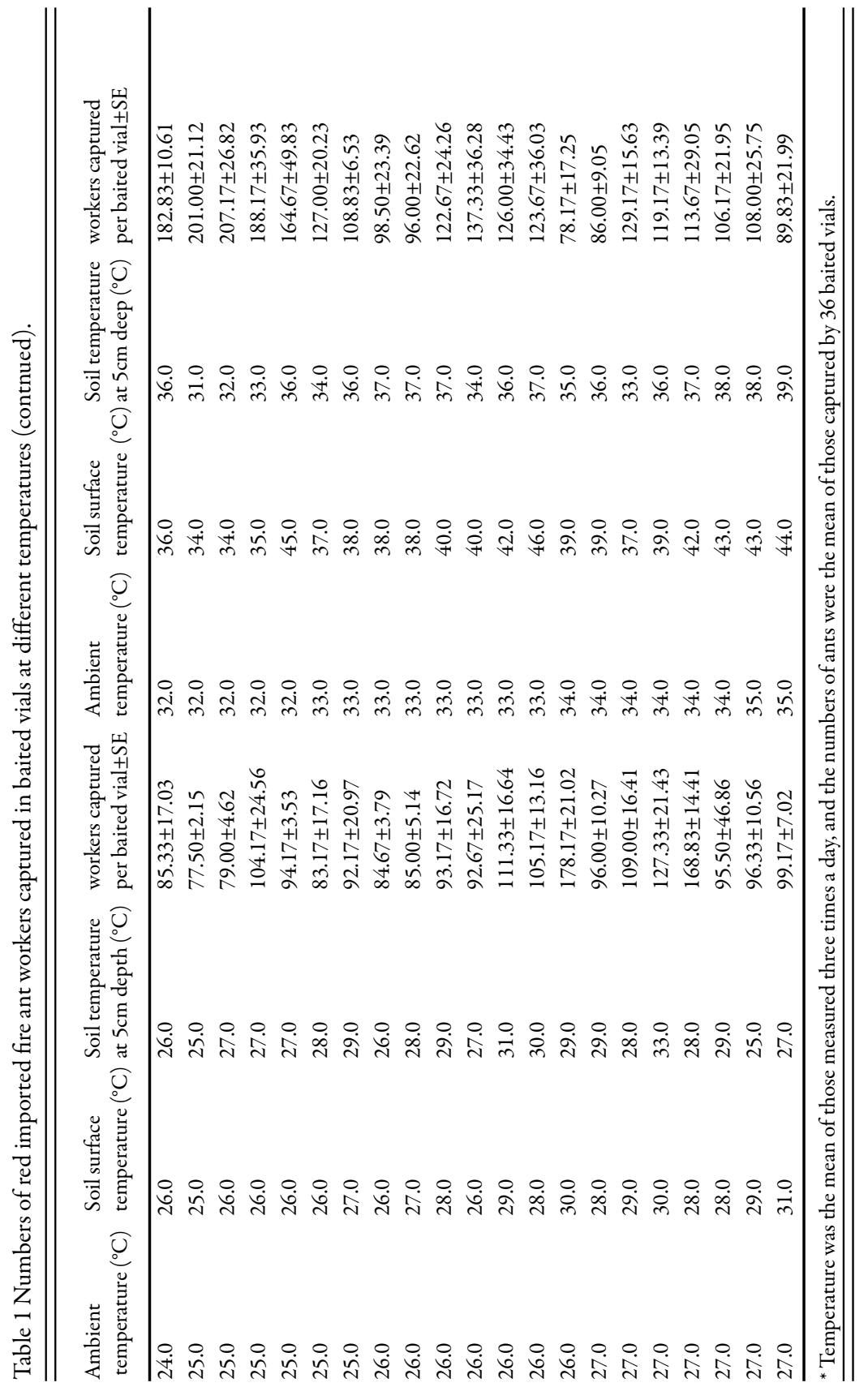


${ }^{\circ} \mathrm{C}$, and $19^{\circ} \mathrm{C}$ respectively. Statistical analyses revealed high significance of the effects of these three temperatures on the foraging activity of fire ants. Specifically, the indices of correlations between the number of worker ants and the ambient temperature, soil surface temperature, and soil temperature at 5 -cm deep were $0.8131(P<0.01, \mathrm{~N}=144), 0.7253(P<0.01, \mathrm{~N}=144)$, and $0.8051(P<0.01, \mathrm{~N}=144)$, respectively.

A function, $\mathrm{Y}=662677.5 /\left(1+34030.4 \mathrm{EXP}\left(-\left(-0.3764 \mathrm{X}+0.0315 \mathrm{X}^{2}-\right.\right.\right.$ $\left.\left.\left.0.000556 \mathrm{X}^{3}\right)\right)\right),(F=111.5, P=0.01)$ was used to test the relationship between different ambient temperatures. $Y$ is the average number of fire ant workers per trap, and $\mathrm{X}$ is the temperature in the three cases. As shown in Fig. 2, the fire ant became active in foraging when the ambient temperature was between 11 and $44^{\circ} \mathrm{C}$.

The function for the effects of ground surface temperature is: $\mathrm{Y}=1245.2$ / $\left(1+168886.5 \operatorname{EXP}\left(-\left(0.5725 \mathrm{X}-0.007683 \mathrm{X}^{2}-0.000013 \mathrm{X}^{3}\right)\right)\right)(F=99.5, P=0.01)$. No ants were captured when the soil-surface temperature was below $10{ }^{\circ} \mathrm{C}$, and foragers were observed even when the temperature was as high as 57

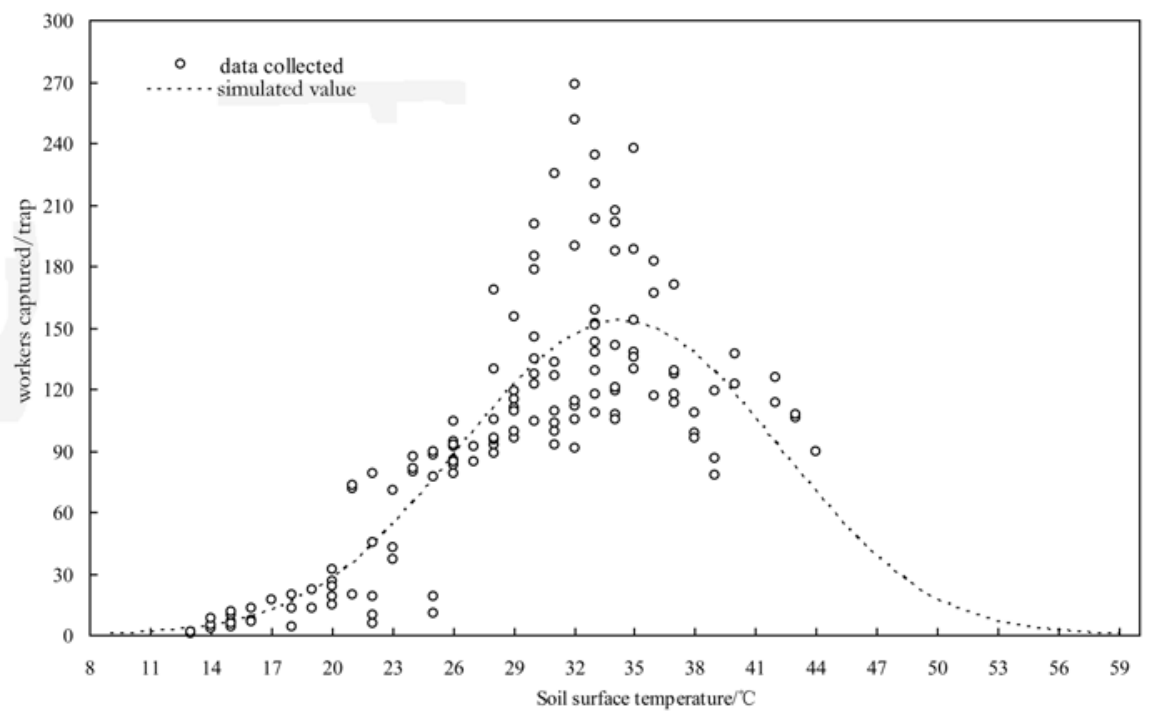

Fig. 3 Dynamics of red imported fire ant workers captured in baited vials at different soil surface temperatures. Each point represents the average number of ants captured per bait trap $(\mathrm{N}=12)$. 
${ }^{\circ} \mathrm{C}$ (Fig.3). These results are consistent with previous report of Porter and Tschinkel (1987).

The best predictor for fire ant foraging activity was the soil temperature at 5-cm deep. The fit function is: $\mathrm{Y}=226944.82 /(1+94298.3 \mathrm{EXP}(-(-$ $\left.\left.\left.0.1373 \mathrm{X}+0.01997 \mathrm{X}^{2}-0.000363 \mathrm{X}^{3}\right)\right)\right)(F=114.4, P=0.01)$. No workers were captured when the soil temperature at 5 -cm deep was below $12^{\circ} \mathrm{C}$ or above $48^{\circ} \mathrm{C}$ (Fig.4).

\section{DISCUSSION}

The foraging of $S$. invicta worker ants was noted when the soil temperature at 5-cm deep was from 12 to $48^{\circ} \mathrm{C}$, and when the ground surface temperature was between 10 and $57^{\circ} \mathrm{C}$. This suggests that the minimum foraging temperature for $S$. invicta worker ants is lower in China than that in Florida, USA (Porter \& Tschinkel 1987), where the low soil temperature at 2-cm deep was $15^{\circ} \mathrm{C}$. The critical minimum and maximum ambient temperatures for fire ant foraging activity were $11{ }^{\circ} \mathrm{Cand} 44^{\circ} \mathrm{C}$, respectively. Indeed, the average ambient temperature in the winters of Guangdong Province is usu-

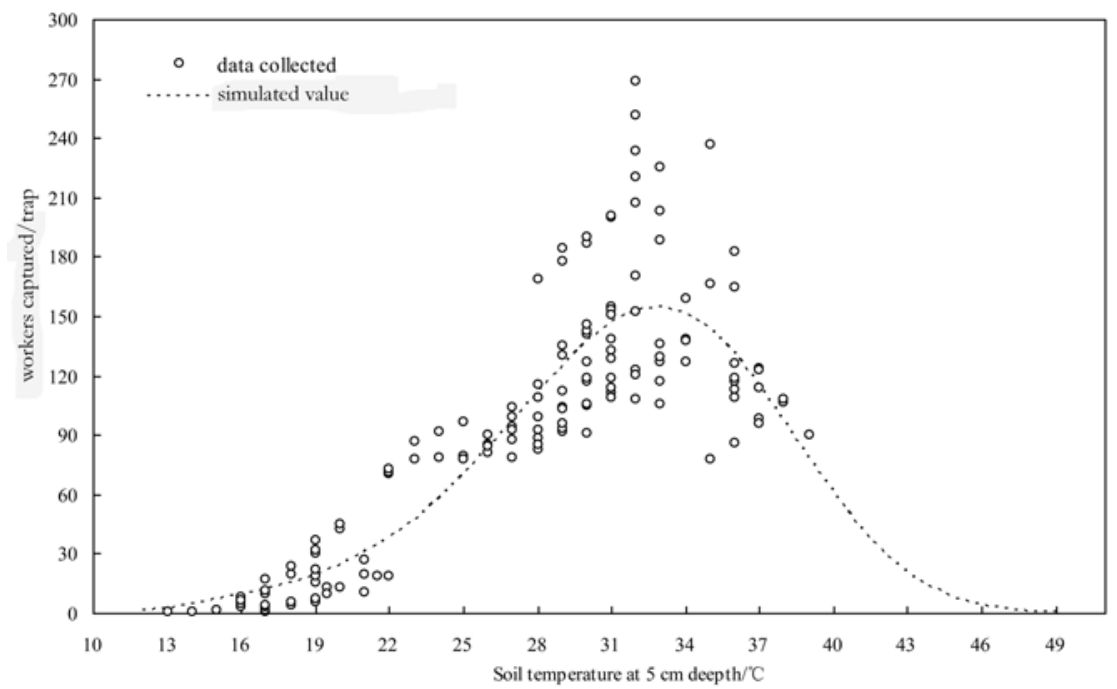

Fig. 4 Dynamics of red imported fire ant workers captured in baited vials at different soil temperatures at 5-cm deep. Each point represents the average number of ants captured per bait trap. 
ally higher than $11.2^{\circ} \mathrm{C}$ (Guangdong Meteorological Administration, www. grmc.gov.cn), indicating that the fire ant foraging can occur throughout the whole year in this region.

It is widely accepted that temperature is the most significant predictor for the foraging activity of fire ants (Porter \& Tschinkel, 1987; Vogt et al. 2003). As was shown in this study, different surroundings with varied temperatures may serve as an important factor for the ants to have different critical minimum and maximum temperatures for foraging. This is consistent with a previous report that field and laboratory imported fire ants had significantly different maximum foraging temperatures $\left(57 \mathrm{vs} 50^{\circ} \mathrm{C}\right.$ ) (Drees et al. 2007).

Toxic bait is an effective method to control fire ants (Lofgren $\&$ Weidhass, 1972). However, it is critical to choose the right time to set the baits, to not only kill the ants most efficiently, but also prevent the baits from being damaged by other animals. In this study, we observed that the most active foraging occurred when the air temperature was at $25-33^{\circ} \mathrm{C}$. Therefore, toxic baits should be set when the temperature is in this range for maximal effects.

\section{ACKNOWLEDGMENTS}

We would like to thank Ningdong Li, and Jun Huang for sample collection and surveys. This work is supported by National Basic Research Program of China (Award\# 2009CB119206) and National Natural Science Foundation of China (Award\# 305712427).

\section{REFERENCES}

Drees, B.B.M., B. Summerlin \& S.B. Vinson 2007. Foraging activity and temperature relationship for the red imported fire ant. Southwestern Entomologist, 32(3):149155.

Bernstein, A.1979. Ruth. Schedules of foraging activity in species of ants. Journal of Animal Ecology, 48(3):921-930.

Briano, J.A., Williams, D.F., D.H. Oi \& L.R. J. Davis 2001. Field host range of the fire ant pathogens Thelohaniasolenopsae (Microsporida: Thelohaniidae) and Vairimorphainvictae (Microsporida: Burenellidae) in South America. Biological Control., 24(2002):98102.

Lofgren, C.S. \& D.E. Weidhaas 1972. On the eradication of imported fire ants: A theoretical appraisal. Bulletin of Entomology Society American, 18:17-20.

Lofgren, C.S., Bartless, F.J., C.E.J. Stringer \& W.A. Banks 1964. Imported fire ant toxic bait studies: further tests with granulated mirex-soybean oil bait. Journal Economic Entomology, 57(5): 695-698. 
Lu, Y.Y., G.W. Liang \& L. Zeng 2008. Study on Expansion Pattern of Red Imported Fire Ant, Solenopsis invicta Buren, in South China. Scientia Agricultura Sinica, 41(4):10531063.

Phillips, S.A., J.A. Rafael \& H.G. Thorvilson 1996. Desiccation resistance in populations of the red imported fire ant (Hymenoptera: Formicidae). Environmental Entomology, 25(2): 460-464.

Porter,D.S.\&R.W.Tschinkel 1987. Foraging in Solenopsisinvicta (Hymenoptera: Formicidae): effects of weather and season. Enviromental entomology, 16(3):802-808.

SAS Institute. 1985. SAS user of guide: statistics, version 5. SAS Institute, Cary, NC.

Vazquez, R.J., S.D. Porter \& J.A. Briano 2006. Field release and establishment of the decapitating fly Pseudacteon curvatus on red imported fire ants in Florida. BioControl, 51(2):207-216.

Vogt, J.T., Smith, W.A., R.A. Grantham \& R. Wright 2003. Effects of temperature and season on foraging activity of red imported fire ants (Hymenoptera: Formicidae) in Oklahoma. Environmental Entomology, 32(3):447-451.

Williams, D.F., Oi, D.H., S.D. Porter \& M. Roberto 2003. Pereira, and Juan A. Briano. Biological control of imported fire ants (Hymenoptera: Formicidae). American Entomologist, 49(3):144-155.

Wojcik, D.P., Craig, R.A., Richard, J.B., Elizabeth, A.F., P. J. Donald \& R.S. Lutz 2001. Red imported fire ants: impact on biodiversity. American Entomologist, 47(1):16-23.

Xu, Y.J., Lu, Y.Y., Huang, J., L.Zeng \& G.W.,Liang2009. Cold hardiness of natural populations of the red imported fire ant, Solenopsis invicta Buren (Hymenoptera: Formicidae) in Shenzhen, Guangdong. Acta Entomologica Sinica, 52(9): 974-983.

Xu Y.J., L., Zeng, Y.Y. Lu \& G.W. Liang 2009. Effect of soil humidity on the survival of Solenopsis invicta Buren workers, 56(4):367-373.

Zeng L., Y.Y., Lu, X.F., He, W.Q. Zhang \& G.W. Liang 2005. Identification of red imported fire ant Solenopsis invicta to invade mainland China and infestation in Wuchuan, Guangdong. Chinese Bulletin of Entomology, 42(2):144-148.

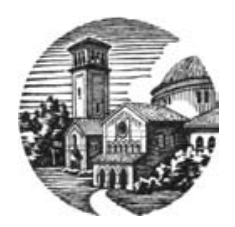


